\title{
Divided Loyalties or Conditional Cooperation? An Experimental Study of Contributions to Multiple Public Goods
}

\author{
Matthew W. McCarter ${ }^{a}$, Anya C. Samak ${ }^{b}$, and Roman M. Sheremeta ${ }^{a}$ \\ a Argyros School of Business and Economics, Chapman University, \\ One University Drive, Orange, CA 92866, U.S.A. \\ ${ }^{\mathrm{b}}$ School of Human Ecology, University of Wisconsin-Madison \\ 1300 Linden Drive, Madison, WI 53706, U.S.A.
}

February 13, 2013

\begin{abstract}
It is common in organizational life to be simultaneously involved in multiple collective actions. These collective actions may be modeled using public good dilemmas. The developing social dilemma literature has two perspectives - the "divided loyalties" and "conditional cooperation" perspectives - that give opposite predictions about how individuals will behave when they simultaneously play two identical public good games. The current paper creates consensus between these social dilemma perspectives by examining cooperative behavior of participants interacting in two public good games with either different or the same group members. In each round, individuals have a common budget constraint across the two games. In support of the conditional cooperator's perspective of social dilemmas, we find that playing two games with different, rather than same, group members increases overall contributions. Over the course of the experiment, participants playing two games with different group members shift their contributions significantly more often toward more cooperative public good games than participants playing with the same group members.
\end{abstract}

JEL Classifications: C72, C73, C91, D03, H41

Keywords: cooperation, conditional cooperation, public good, experiments, group composition

Corresponding author: Matthew W. McCarter, mccarter@chapman.edu

Authors are listed in alphabetical order and contributed equally to this study. We thank Tim Cason and Bryan Bonner for helpful comments. Any remaining errors are ours. 


\section{Introduction}

An assistant professor sits at her desk staring at several unfinished projects. Each project is with different co-authors and needs additional data collection. Like her co-authors, she must decide how to disperse her limited research budget, time, and effort across these projects.

A proud parent of an honors student involves himself simultaneously on the boards of his son's Boy Scout Troop and the neighborhood Homeowners' Association. Each week he must decide how much time to allocate between these two groups' activities.

These scenarios remind us that many of the shared benefits enjoyed in organizational settings come from the aggregated prosocial behavior of individuals who face constrained resources (Fuster and Meier 2010). The necessity of prosocial behavior to produce these shared benefits creates a public goods dilemma: a situation where individuals experience tension between incurring a private cost in the short-run - e.g., sacrificed time, money, and effort - to generate collective benefits in the long-run - e.g., a publication that gives all co-authors recognition, or greater funding to a charity (Samuelson 1954). The tension between being prosocial and pro-self results in many public goods being under-produced or not produced at all (Olson 1995; Ledyard 1995).

These vignettes also highlight that individuals often straddle multiple collective efforts simultaneously. Cross and Guyer (1980), in their discussion of "hybrid" social dilemmas, were the first to suggest that individuals often face multiple collective actions simultaneously. Despite over three decades of discussion about cooperation (or prosocial) behavior when facing multiple social dilemmas simultaneously (e.g., Janssen and Ostrom 2006; López-Pérez 2012), little empirical work has surfaced. The empirical work that does exist does not allow for transfers of endowments across social dilemmas (e.g., Falk et al. 2013) or considers the effects of participating in multiple different, rather than same, games (e.g., Cason et al. 2012; Bednar al. 2012; Savikhin and Sheremeta 2013). From a pragmatic standpoint, understanding how facing 
multiple, simultaneous social dilemmas affects prosocial behavior would be useful for organizations that construct policies for individuals engaging in collective action in different (and same) groups or teams.

From a theoretical standpoint, addressing this question would resolve competing predictions current in the social dilemma literature. Two perspectives in the social dilemma literature give opposite predictions about how individuals will behave when they simultaneously play two identical public good games. One perspective, in organizational behavior and social psychology, suggests that straddling multiple collective efforts simultaneously would negatively affect cooperation because of "divided loyalties” (e.g., McCarter and Northcraft 2007; Wit and Kerr 2002); while a second perspective, from behavioral economics on "conditional cooperation,” predicts the opposite relationship (e.g., Fischbacher et al. 2001; Gächter 2007).

The current paper provides resolution and extension to these competing predictions through a laboratory experiment where participants, under a single budget constraint, allocate money between two public good games. These public good games are patterned after Isaac and Walker's (1988) voluntary contribution mechanism (VCM) paradigm. In seeking to "create consensus” between these perspectives (Hollenbeck 2008), we extend both perspectives by examining how prosocial behavior changes depending on whether individuals play two games with either different or the same group members. We find that prosocial behavior in greater when individuals face multiple social dilemmas with different group members compared to the same group members, and this difference can be explained by the observation that participants act as conditional cooperators. When making choices in two VCMs played with different group members, individuals are influenced by the behavior of fellow group members in both VCMs. However, when making choices in two VCMs played with the same group members, individuals 
are influenced to react in each game only to the behavior of group members in that VCM. We also find that over the course of the experiment, participants allocating contributions between public goods with different groups shift their contributions significantly more often towards more cooperative VCMs than in the other condition. These participants in the different groupmember condition often choose to contribute more than half of their endowment to only one of the two VCMs. Moreover, the exact contribution to a given VCM depends both on previous individual contributions (individual disposition effect) and previous group contributions in both VCMs (social interaction effect).

In resolving the competing predictions from the social dilemma literature, the current paper makes three contributions. First, our resolution to the disparate predictions extends beyond the boundary of social dilemmas into group dynamics. We provide one possible answer to an important question (Fried et al. 1988; O'Leary et al. 2011; Postrel 2009): how does the composition across groups influence prosocial behavior through indirect social interaction? Second, while the existing social dilemma paradigm often assumes that individuals are involved in one social dilemma, we enhance the ecological validity of the social dilemma paradigm by considering a circumstance ubiquitous to organizational and social life: individuals making interdependent resource allocation decisions while straddling multiple collective actions simultaneously. Third, our findings provide insights for policy makers: a social planner faced with a task of assembling work teams may increase economic and collective welfare by assigning participants to work with different, rather than same, group members. 


\section{Literature Review and Theoretical Background}

\subsection{Theoretical Background and Competing Hypotheses}

Social dilemmas are broadly defined as situations in which group and private interests diverge such that everyone doing what is in their own best self-interest results in an outcome that is in the group's worst interest (Dawes 1980). While there is temptation to free ride and offensively undercontribute toward the public good, individuals more often undercontribute defensively: they fear that others will free ride on their contributions (Rockmann and Northcraft 2008; Yamagishi and Sato 1986). As a consequence of this fear of exploitation, individuals conditionally cooperate and contribute more toward the public good when they know that others are also contributing (e.g., Fischbacher et al. 2001). While there is little dispute among social dilemma researchers about the motivations for cooperation and defection, "there are two clear lines of discrepant thought simultaneously existing in the literature” regarding prosocial behavior as a function of being involved in several social dilemmas simultaneously (Hollenbeck 2008: 20).

\section{Divided Loyalties}

Social dilemma scholarship in organizational behavior and social psychology observes that individuals can be "nested" simultaneously within multiple groups who are all facing a social dilemma with a fixed pool of resources (Polzer et al. 1999; Wit and Kerr 2002). Belonging to multiple groups with different members who are each facing a social dilemma may create a tension of allegiances, encouraging an individual to "fear [their partner's] interests no longer rest with only [their group] but with other [groups]” (McCarter and Northcraft 2007: 504). The nested social dilemma literature would predict that, compared to situations where an individual 
faces multiple social dilemmas with the same people, facing multiple social dilemmas with different people may lead an individual to question the others' allegiance to interests (see McCarter and Northcraft 2007, proposition 3). As a consequence the potential for "divided loyalties”, an individual is motivated to protect his/her private resources and defensively undercontribute toward the public good (McCarter et al. 2010). ${ }^{1}$ Thus, because of fear of stressed allegiances, the divided loyalties perceptive to social dilemmas predicts the following:

Hypothesis 1: Individuals will contribute less toward multiple public goods when involved in different groups as compared to individuals involved in the same group.

\section{Conditional Cooperation}

Behavioral economics research on "conditional cooperation" in social dilemmas makes a different prediction (Fischbacher et al. 2001). Gächter (2007) points out that the existence of conditional cooperators can explain several puzzles observed in the VCM experiments. For example, it can explain why contributions to the public good decline over time. The reason is that conditional cooperators stop cooperating after they learn that others free ride by not contributing to the public good. This burgeoning research is based on the observation that groups form their own norms that influence individual-member behavior across different situations (Jacobs and Campbell 1961). Ichino and Maggi’s (2000) field study on shirking behavior finds that an individual's contribution towards a group's interest is a function of how others in the group behave (also termed social [or group] interaction). In considering the strong normative influence often imposed on an individual by a group (Deutsch and Gerard 1955), working with different groups on related tasks (as compared to with the same group) provides flexibility not

\footnotetext{
${ }^{1}$ Besides divided loyalties, individuals may be reluctant to cooperate in large groups because of mistrust (McCarter and Sheremeta, 2013).
} 
only in where to allocate resources but with whom individuals work (O'Leary et al. 2011). Related literature suggests that roughly $40 \%-80 \%$ of individuals display conditionally cooperative behavior in the lab (Fischbacher et al. 2001; Gächter 2007; Hermann and Thoni 2009; Kocher et al. 2008). This type of behavior is often referred to as a social interaction effect: conditional cooperators adapt their behavior in response to the behavior of their group members - they free ride if other group members free ride and they cooperate if others cooperate.

In relation to the current study, being a member of two groups composed of different participants increases the likelihood that conditional cooperators will be able to sustain cooperation (at least in one group that is more cooperative). The increase in likelihood of having more conditional cooperators in one of the two groups increases the likelihood of others following a cooperative signal. In addition, conditional cooperators participating in two groups with different fellow group members may use the lower-cooperating group as a reference point with which to compare the higher-cooperating group, always contributing more to the highercooperating group. In contrast, conditional cooperators in the treatment with same group members do not have this reference point since they know that the level of pro-sociality of fellow members across groups is the same. Thus, the related work on conditional cooperation and social interaction literature would predict:

Hypothesis 2: Individuals will contribute more toward multiple public goods when involved in different groups compared to individuals involved in the same group. 


\subsection{Overview of the Current Study Related to Previous Research}

Existing studies on multiple public goods can be broken into two groups. The first group decomposes a single public good into multiple parts, while the second group considers two different public goods. Our experiment is close in design to the former. Similar to our treatment with same group members across VCMs, existing studies consider simultaneous interaction in several public goods, either breaking a single public good into parts or presenting multiple public goods (Bernasconi et al. 2009; Biele et al. 2008; Fellner and Lunser 2008; Falk et al., 2013). Bernasconi et al. (2009) investigate an “unpacked” VCM, comparing contributions when a single group contributes to one VCM as compared to multiple VCMs, and find that contributions are greater under the unpacked treatment, although this increase is not sustained for the duration of the session. Biele et al. (2008) introduce a "pairs” treatment by breaking up 4-person groups into two 2-person groups, and find that participants contribute more in the smaller groups. Fellner and Lunser (2008) study a local and a global public good, where the local public good has a higher marginal benefit but fewer group members while the global public good is Pareto optimal but has a greater number of group members. Fellner and Lunser (2008) find that there are initial attempts to cooperate in the global public good, but increased cooperation in the local public good is observed over time - an effect attributed to group size differences. Falk et al. (2013) utilize a design similar to our treatment with different group members across groups and compare coordination and contributions in groups of different individuals playing two identical VCM games.

The main difference of our study as compared to previous work is that we investigate simultaneous decision-making both with same and different group members under a shared budget constraint. The shared budget constraint allows for the possibility of social interactions, 
and the direct comparison of same versus different group members allows us to expose participants to a controlled set of fellow group members in order to better understand the role of conditional cooperation. This is the first study to consider the effect of social interactions when groups are different or the same. Unlike most of the work on public good with same member interaction, our experiment uses a shared budget constraint, effectively allowing participants to shift their entire endowment to just one of the public goods. This aspect of the design is also more realistic, because in practice individuals participate in many environments simultaneously and are constrained by a single budget constraint when choosing between various activities.

\section{Experimental Design and Procedure}

The experiment was conducted at a large public university in the Central United States. Participants were recruited from a pool of undergraduate students. We conducted two treatments: a VCM-Same treatment in which two VCMs were played simultaneously by each individual with the same group members in each VCM, and a VCM-Different treatment in which two VCMs were played simultaneously by each individual with one set of group members in one of the VCMs and a set of different group members in the other VCM. A total of 104 participants participated in 6 sessions, with 40 participants participating in 2 sessions of VCM-Same (20 participants per session) and 64 participants participating in 4 sessions of VCM-Different (16 participants per session).

The computerized experimental sessions used z-Tree (Fischbacher 2007) to record participants' decisions and also to record the order of decisions. Participants were given the instructions, shown in the appendix, at the beginning of the session and the experimenter read the instructions aloud. In each session of VCM-Same, 20 participants were randomly assigned to a 
group of 4 players, and played both games with the same group members. In each session of VCM-Different, 16 participants were randomly assigned to a group of 4 players in one game and to a different group of 4 players in the other game, such that no participants played one game with any of their group members from the other game. The group composition remained fixed for all 20 rounds of the experiment in both treatments. All participants participated in only one session of this study. Some students had participated in other economics experiments that were unrelated to this research.

In each round, the two VCMs were displayed side by side on the same screen, see Figure 1. At the beginning of each round, each participant received an endowment of 160 francs, which could be transferred between VCMs. Each participant chose a portion of the endowment to contribute to one or both of the VCMs, and chose to keep the remaining portion of the endowment in a private account. Each player's contribution to the public good was multiplied by 0.4 and the total of all contributions given to each of the 4 players in the group in each VCM. Each participant kept the remainder of the 160-franc endowment that he did not allocate to either VCM. Participants did not know others' decisions before making their own decisions. After all participants made their decisions, the sum of all contributions in each group was displayed on the output screen together with the outcome, and earnings in each round were determined as the sum of the endowment kept in the private account and the earnings from the public good in each game. Participants recorded their results in a record sheet, and then moved on to the next round.

At the end of the experiment, two rounds from the game were selected for payment using a random draw from a bingo cage. Experimental francs were used throughout the experiment, with a conversion rate of 25 francs $=\$ 1$. Participants earned $\$ 17$ on average, and sessions 
(including instruction time) lasted approximately 70 minutes. Participants also completed a demographic questionnaire at the end of each session.

\section{Experiment Results}

\subsection{Result Overview}

Table 1 reports the average contributions and payoffs across both treatments, separately for each VCM. We find that in each treatment, participants make relatively similar contributions to both VCMs on average. Figure 2 displays, by treatment, the average contribution (across both VCMs) over all 20 rounds of the experiment.

\section{[Insert Table 1 about here]}

Comparing the two treatments using a two-sample t-test, we find that contributions are significantly higher when group composition is different across both VCMs as compared to when composition is the same across the two VCMs $\left(\mathrm{M}_{1}=17.7, \mathrm{SD}_{1}=13.2, \mathrm{n}_{1}=64\right.$ versus $\mathrm{M}_{2}=$ 11.3, $\mathrm{SD}_{2}=14.2, \mathrm{n}_{2}=40$; t-test, $\left.\mathrm{p}=0.02\right){ }^{2}$ The same conclusion is supported even when using a very conservative non-parametric test that treats each group of participants as one independent observation $\left(\mathrm{M}_{1}=17.7, \mathrm{SD}_{1}=4.4, \mathrm{n}_{1}=4\right.$ versus $\mathrm{M}_{2}=11.3, \mathrm{SD}_{2}=12.8, \mathrm{n}_{2}=10$; Wilcoxon ranksum test, $\mathrm{p}=0.05$ ). ${ }^{3}$ These results provide evidence in support of Hypothesis 2 (derived from conditional cooperators literature) and not Hypothesis 1 (derived from divided loyalties literature), suggesting that individuals contribute more toward multiple public goods when involved in different groups compared to individuals involved in the same group.

\footnotetext{
${ }^{2}$ In conducting this t-test, we used the average contribution per subject across both VCMs and over all 20 periods of play as one observation.

${ }^{3}$ In the VCM-Same treatment one independent observation is a group of 4 subjects $(40$ subjects $=10$ groups $=10$ independent observations), while in the VCM-Different treatment one independent observation is one session (64 subjects $=4$ sessions $=4$ independent observations).
} 


\subsection{Conditional Cooperation}

Hypothesis 2 suggests conditional cooperation as an explanation for the difference in contributions between the VCM-Different and VCM-Same treatments. For this part of the analysis, we define cooperators as participants who contribute more than $75 \%$ of the endowment (Andreoni and Petrie 2004; Savikhin and Sheremeta 2013). These are the individuals who either have an intrinsic motivation to be more prosocial or who conditionally cooperate based on observing other cooperators. Table 2 reports the distribution of cooperators as a percentage of total number of individuals. Comparing the two treatments, we find that in the first round of the experiment there are marginally more cooperators in the VCM-Same than in the VCM-Different treatment, but this difference is not statistically significant $\left(\mathrm{M}_{1}=0.203, \mathrm{SD}_{1}=0.051, \mathrm{n}_{1}=64\right.$ versus $\mathrm{M}_{2}=0.250, \mathrm{SD}_{2}=0.069, \mathrm{n}_{2}=40$; t-test, $\mathrm{p}=0.71$ ). However, in the last 10 rounds of the experiment, there are twice as many cooperators left in the VCM-Different than in the VCMSame treatment $\left(\mathrm{M}_{1}=0.059, \mathrm{SD}_{1}=0.017, \mathrm{n}_{1}=64\right.$ versus $\mathrm{M}_{2}=0.025, \mathrm{SD}_{2}=0.009, \mathrm{n}_{2}=40$; $\mathrm{t}$ test, $\mathrm{p}=0.07$ ). This observation provides additional support for Hypothesis 2, suggesting that participants who interact with two different groups of individuals may learn how to maintain cooperation better than participants who interact with only one group of individuals.

[Insert Table 2 about here]

How do participants maintain better cooperation in the VCM-Different as compared to in the VCM-Same treatment? Table 3 displays the average contribution in round $t$ conditional on group contribution in round $t$ - 1 . When examining the VCM-Same treatment, we find that if the group contribution in round $t-1$ to the VCM-1 is greater than the group contribution to the VCM2, participants choose to contribute $40 \%$ more in round $t$ to the VCM-1 than to the VCM-2 (12.8 versus 9.1). Similarly, if the group contribution in round $t-1$ to the VCM-2 is more than the group 
contribution to the VCM-1, participants choose to contribute $76 \%$ more in round $t$ to the VCM-2 than to the VCM-1 (11.3 versus 6.4). These findings suggest that participants in the VCM-Same treatment shift their contributions to the VCMs with higher contribution rates - thereby acting as conditional cooperators across games. The magnitude of this shift ranges from $40 \%$ to $76 \%$. When examining the VCM-Different treatment, we find a similar type of behavior; however, the magnitude of shifts is drastically different. If the group contribution in round $t-1$ to the VCM- 1 (VCM-2) is greater than the group contribution to the VCM-2 (VCM-1), participants choose to contribute $221 \%$ (271\%) more in round $t$ to the VCM-1 (VCM-2). The finding that participants in the VCM-Different treatment shift their contributions significantly more than participants in the VCM-Same treatment can help explain the difference in overall contribution rates across treatments (t-test, both p-values $<0.01$; Wilcoxon rank-sum test, both p-values $<0.05$ ). ${ }^{4}$

[Insert Table 3 about here]

Additional evidence of greater shifting of contributions in the VCM-Different treatment relative to the VCM-Same treatment comes from comparing the number of instances when participants choose to contribute more than half of their endowment to one of the VCMs. Specifically, we find that in $2.3 \%$ of instances, participants transfer more than half of their endowment to one of the two VCMs in the VCM-Same treatment. In the VCM-Different treatment, this number is more than doubled to $5.5 \%$ of instances (t-test, $\mathrm{p}=0.04, \mathrm{n}_{1}=64, \mathrm{n}_{2}=$ 40; Wilcoxon rank-sum test, $\mathrm{p}=0.10, \mathrm{n}_{1}=4, \mathrm{n}_{2}=10$ ). Note that the number of participants that transfer more than half may be low overall because participants tend to keep a significant portion of their endowment rather than to give it to the public good. Our findings comport with the

\footnotetext{
${ }^{4}$ We constructed 10 independent observations in the VCM-Same treatment $(40$ subjects $=10$ groups $=10$ independent observations) and 4 observations in the VCM-Different treatment (64 subjects $=4$ sessions $=4$ independent observations). Each observation was the average difference between the contribution to the VCM-1 (VCM-2) and VCM-2 (VCM-1), conditional on higher group contribution to the VCM-1 (VCM-2) in the previous round.
} 
results of Falk et al. (2013), who looked at participants participating in VCMs with different group members and found evidence for social interactions (i.e., participants contribute more to groups in which others are also contributing).

\subsection{Determinants of Contributions}

Table 4 reports estimates of panel regressions conducted separately for each treatment and each VCM. In these regressions, the dependent variable is participant's contribution to the VCM-1 (regressions 1 and 3) and to the VCM-2 (regressions 2 and 4). The independent variables are VCM-1-lag (lagged individual contribution to the VCM-1), VCM-2-lag (lagged individual contribution to the VCM-2), group-VCM-1-lag (lagged group contribution to the VCM-1), group-VCM-2-lag (lagged group contribution to the VCM-2), and a constant. All regressions use a random effects error structure for the individual participants to account for repeated measures, and a period trend to account for learning. Standard errors are clustered at the matching group level.

[Insert Table 4 about here]

In the VCM-Same treatment, according to the estimation results in regression (1), the main determinants of contribution in the VCM-1 are VCM-1-lag and group-VCM-1-lag, indicating that the two major factors influencing contributions are an individual disposition towards cooperation (i.e., tendency of a participant to contribute continually to the VCM) and social interaction (i.e., contributing to the VCM-1 conditional on group cooperation level). Similar results are reported in regression (2) for the VCM-2.

In the VCM-Different treatment, the determinants of contribution are more complex. According to the estimation results in regression (3), the determinants of contribution in the 
VCM-1 are VCM-1-lag and VCM-2-lag, suggesting strong individual disposition effects. More interesting is the fact that the contribution in the VCM-1 is positively correlated with groupVCM-1-lag and negatively correlated with group-VCM-2-lag. This suggests that in the VCMDifferent treatment, conditional cooperators are more responsive to the behavior of the two groups. They contribute more to the VCM-1 if they observe a cooperative behavior in the VCM1 in the previous round, but they contribute less to the VCM-1 if they observe more cooperative behavior in the VCM-2 in the previous round. This is also true when we examine regression (4) for the VCM-2. Overall, these findings reveal a mechanism used by subjects to achieve higher cooperation in the VCM-Different than in the VCM-Same treatment: subjects in the VCMDifferent treatment conditionally shift their contributions from a less cooperative group to a more cooperative group (there is no such evidence in the VCM-Same treatment).

\section{Discussion and Conclusion}

We experimentally investigated simultaneous decision-making in two public good games with same and different group members. In both treatments, participants were limited by a single budget constraint and had to choose how to allocate their endowment across two public goods. Compared to experiments that investigate behavior in single games in isolation, our study may be more relevant to practical contexts, including contributions to volunteer organizations or public projects, and interactions in organizational or social groups. We find that playing two public good games in different groups results in significantly greater overall contributions when compared to playing two public good games in same groups. The difference can be explained by the finding that participants act as conditional cooperators. Although participants have inherent individual disposition towards cooperation (i.e., their contributions are correlated across different 
rounds of the experiment), they are also conditionally cooperative (i.e., their contributions are correlated with their group contributions across different rounds of the experiment). Moreover, we find that over the course of the experiment, participants in the VCM-Different treatment shift their contributions significantly more towards more cooperative VCMs than in the VCM-Same treatment.

As the social dilemmas paradigm has developed since Dawes’ (1980) seminal paper, two competing lines of social research have emerged regarding cooperation behavior when facing multiple social dilemmas: a "divided loyalties" perspective and a "conditional cooperation" perspective. The purpose of the current research was to create consensus between these competing literatures. The choice of where to contribute resources when facing multiple social dilemmas with different groups led to greater overall cooperation because conditional cooperators were able to band together. This finding supports the conditional cooperation proposition of thought (derived from behavioral economics literature) on cooperation in multiple, simultaneous social dilemmas compared to the divided loyalties proposition (derived from organizational behavior / social psychology literature).

Our findings also push the current social dilemma paradigm by considering the role of discretion. Social dilemma research primarily focuses on the discretion about whether or not to contribute resources toward collective action (Calvert 1992; Zeng and Chen 2003). Even when examining multiple group membership, most social dilemma literature still focuses on discretion over whether to improve collective welfare or individual welfare (Polzer et al. 1999; Wit and Kerr 2002). The current paper introduces a second source of discretion - which collective action to undertake. Indeed, while individuals can always decide whether to assist or impede collective action, we observe that individuals can also decide which collective action to assist and which to 
impede. Examining this source of discretion in the conversation of social dilemmas enhances the paradigm's ecological validity and leaves room for answering the trans-paradigmatic question, what can collectives do to look attractive to conditional cooperators?

We conclude with offering several additional avenues for future research. Given that many activities in practice involve simultaneous decision-making in multiple environments, it is important to study how the nature of these environments impacts cooperative behavior. For example, would we still observe higher cooperation when playing two games with different, rather than same, group members if, instead of two public good games, participants played in two tournaments? Investigating different environments will allow for the development of a unifying theory of simultaneous decision-making. Another avenue for future research is to study behavioral processes employed by participants when playing ensembles of games. We have already suggested how social interaction and individual disposition effects can explain the process of individual and group decision-making in our experiment. Obviously, there may be other processes involved that can help explaining behavior in environments with multiple games. Finally, it is important to investigate how behavioral regularities observed in more complex settings can be used to design more efficient economic and management systems. We leave these extensions for future research. 


\section{References}

Andreoni, J., \& Petrie, R. (2004). Public goods experiments without confidentiality: a glimpse into fund-raising. Journal of Public Economics, 88, 1605-1623.

Bednar, J., Chen, Y., Liu, T.X., \& Page, S. (2012). Behavioral spillovers and cognitive load in multiple games: An experimental study. Games and Economic Behavior, 74, 12-31.

Bernasconi, M., Corazzini, L., Kube, S., \& Marechal, M. (2009). Two are better than one! Individuals' contributions to “unpacked” public goods. Economic Letters, 104, 31-33.

Biele, G., Rieskamp, J., \& Czienskowski, U. (2008). Explaining cooperation in groups: Testing models of reciprocity and learning. Organizational Behavior and Human Decision Processes, 106, 89-105.

Brewer, M.B. (1991). Self-evaluation effects of interpersonal versus intergroup social comparison. Journal of Personaliy and Social Psychology, 66, 268-275.

Brewer, M.B., \& Gardner, W. (1996). Who is this "We"? Levels of collective identity and self representations. Journal of Personality and Social Psychology, 71, 83-93.

Calvert, R. (1992). Leadership and its basis in problems of social coordination. International Political Science Review, 13, 7-24.

Cason, T., Savikhin, A., \& Sheremeta, R. (2012). Behavioral spillovers in coordination games. European Economic Review, 56, 233-245.

Cross, J.G., \& Guyer, M.J. (1980). Social traps. University of Michigan Press, Ann Arbor, MI.

Dawes, R.M. (1980). Social dilemmas. Annual Review of Pychology, 31, 169-193.

Deutsch, M., \& Gerard, H.B. (1955). A study of normative and informational social influences upon individual judgement. Journal of Abnormal and Social Psychology, 51, 629-636.

Falk, A., Fischbacher, U., Gächter, S., \& Effects, S.I. (2013). Living in two neighborhoods social interaction effects in the laboratory. Economic Inquiry, 51, 563-578.

Fellner, G., \& Lunser, G. (2008). Cooperation in local and global groups. Working Paper.

Fischbacher, U. (2007). Z-tree: Zurich toolbox for ready-made economic experiments. Experimental Economics, 10, 171-178.

Fischbacher, U., Gächter, S., \& Fehr, E. (2001). Are people conditionally cooperative? Evidence from a public goods experiment. Economics Letters, 71, 397-404.

Fried, B.J., Leatt, P., Deber, R., \& Wilson, E. (1988). Multidisciplinary teams in health care: Lessons from oncology and renal teams. Healthcare Management Forum, 1, 28-34.

Fuster, A., \& Meier, S. (2010). Another hidden cost of incentives: The detrimental effect on norm enforcement. Management Science, 56, 57-70.

Gächter, S. (2007). Conditional cooperation. Behavioral regularities from the lab and the field and their policy implications, in Bruno S. Frey and Alois Stutzer (eds): Economics and Psychology. A Promising New Cross-Disciplinary Field. CESifo Seminar Series. The MIT Press.

Hermann, B., \& Thoni, C. (2009). Measuring conditional cooperation: a replicatoin study in Russia. Experiemental Economics, 12, 87-92.

Hollenbeck, J.R. (2008). The role of editing in knowledge development: Consensus shifting and consensus creation. In Y. Baruch \& A. M. Konrad \& H. Aguinus \& W. H. Starbuck (Eds.), Journal editing: Opening the black box: 16-26. San Francisco, CA: Jossey Bass.

Ichino, A., \& Maggi, G. (2000). Work environment and individual background: Explaining regional shirking differentials in a large Italian firm. Quarterly Journal of Economics, 115, 1057-1090. 
Isaac, M.R., \& Walker, J.M.. (1988). Communication and free-riding behavior: the voluntary contribution mechanism. Economic Inquiry, 26, 585-608.

Jacobs, R.C. \& Campbell, D.T. (1961). The perpetuation of an arbitrary tradition through several generations of a laboratory microculture. Journal of Abnormal and Social Psychology, 62, 649-658.

Janssen, M.A., \& Ostrom, E. (2006). Governing social-ecological systems. L. Tesfatsion, K.L. Judd, eds. Handbook of computational economics. Elsevier, Oxford, UK, 1465-1509.

Kocher, M.G., Cherrt, T., Kroll, S., Netzer, R.J., \& Sutter, M. (2008). Conditional cooperation on three continenets. Economics Letters, 101, 175-178.

Ledyard, J. (1995). Public goods: A survey of experimental research. In J. Kagel and A.E. Roth (Eds.) Handbook of experimental economics, Princeton, NJ.

López-Pérez, R. (2012). The power of words: A model of honesty and fairness. Journal of Economic Psychology, 33, 642-658.

McCarter, M.W., \& Northcraft, G.B. (2007). Happy together?: Insights and implications of viewing managed supply chains as a social dilemma. Journal of Operations Management, 25, 498-511.

McCarter, M.W., Rockmann, K.W., \& Northcraft, G.B. (2010). Is it even worth it? The effect of loss prospects in the outcome distribution of a public goods dilemma. Organizational Behavior and Human Decision Processes, 111, 1-12.

McCarter, M.W., \& Sheremeta, R.M. (2013). You Can’t Put Old Wine in New Bottles: The Effect of Newcomers on Coordination in Groups. PLOS ONE, 8, e55058.

O’Leary, M., Moretensen, M., \& Woolley, A. (2011). Multiple team memebership: A theoretical model of its effects on productivity and learning for individuals and teams. Academy Management Review, 36, 461-478.

Olson, M. (1995). The logic of the collective. Cambridge: Harvard University Press.

Polzer, J.T., Stewart, J.L., \& Simmons, J.L. (1999). A social categorization explanation for framing effects of nested social dilemmas. Organizational Behavior and Human Decision Processes, 79, 154-178

Postrel, S. (2009). Multitasking teams with variable complementarity: challenges for capability management. Academy of Management Review, 34, 273-296.

Rockmann, K.W., \& Northcraft, G.B. (2008). To be or not to be trusted: The influence of media richness on defection and deception. Organizational Behavior and Human Decision Processes, 107, 106-122.

Samuelson, P.A. (1954). The pure theory of public expenditure. Review of Economics and Statistics, 36, 687-689.

Savikhin, A.C., \& Sheremeta, R.M. (2011). Visibility of contributors and cost of information: An experiment on public goods. Working paper.

Savikhin, A.C., \& Sheremeta, R.M. (2013). Simultaneous decision-making in competitive and cooperative games. Economic Inquiry, forthcoming.

Wit, A.P., \& Kerr, N.L. (2002). "Me versus just us verus all” categorization and cooperation in nested social dilemmas. Jounral of Personality and Social Psychology, 83, 616-637.

Yamagishi, T., \& Sato, K. (1986). Motivational basis of the public goods problem. Journal of Personality and Social Psychology, 50, 67-73.

Zeng, M., \& Chen, X.-P. (2003). Achieving cooperation in multiparty alliances: A social dilemma approach to partnership management. Academy of Management Review, 28, 587-605. 
Table 1: Average Contribution and Payoffs in each VCM

\begin{tabular}{lccc}
\hline \hline Treatment & & Contribution & Payoff \\
\hline \multirow{3}{*}{ VCM-Same } & VCM-1 & $11.8(24.2)$ & $7.1(19.2)$ \\
& VCM-2 & $10.8(21.2)$ & $6.5(17.9)$ \\
\cline { 2 - 4 } & Average & $11.3(20.1)$ & $6.8(16.1)$ \\
\hline \multirow{3}{*}{ VCM-Different } & VCM-1 & $16.4(28.1)$ & $9.8(24.2)$ \\
& VCM-2 & $19.1(29.9)$ & $11.4(25.1)$ \\
\cline { 2 - 4 } & Average & $17.7(22.3)$ & $10.6(18.9)$ \\
\hline
\end{tabular}

Standard deviation in parentheses.

Table 2: Distribution of Leaders and Laggards

\begin{tabular}{lcc}
\hline \hline Treatment & Round & Cooperators \\
\hline \multirow{3}{*}{ VCM-Same } & 1 & $25.0 \%$ \\
& $2-10$ & $8.3 \%$ \\
& $11-20$ & $2.5 \%$ \\
\cline { 2 - 3 } VCM-Different & 1 & $20.3 \%$ \\
& $2-10$ & $8.5 \%$ \\
& $11-20$ & $5.9 \%$ \\
\hline
\end{tabular}

Table 3: Contribution in Round $t$ Conditional on Group Contribution in Round $t-1$

\begin{tabular}{lccc}
\hline \hline Treatment & & $\begin{array}{c}\text { Group Contribution } \\
\text { in Round } t-1\end{array}$ & $\begin{array}{c}\text { Contribution } \\
\text { in Round } t\end{array}$ \\
\hline \multirow{5}{*}{ VCM-Same } & VCM-1 & VCM-1 $\geq$ VCM-2 & $12.8(26.2)$ \\
& VCM-2 & VCM-1 $\geq$ VCM-2 & $9.1(20.6)$ \\
& VCM-1 & VCM-1 $<$ VCM-2 & $6.4(14.5)$ \\
& VCM-2 & VCM-1 $<$ VCM-2 & $11.3(19.5)$ \\
\hline \multirow{5}{*}{ VCM-Different } & VCM-1 & VCM-1 $\geq$ VCM-2 & $19.7(32.6)$ \\
& VCM-2 & VCM-1 $\geq$ VCM-2 & $8.9(18.4)$ \\
& VCM-1 & VCM-1 $<$ VCM-2 & $10.7(19.1)$ \\
& VCM-2 & VCM-1 $<$ VCM-2 & $29.0(30.0)$ \\
\hline
\end{tabular}

Standard deviation in parentheses. 
Table 4: Random Effect Models of Individual Participant Contributions

\begin{tabular}{|c|c|c|c|c|}
\hline \multirow{3}{*}{$\begin{array}{l}\text { Treatment } \\
\text { Individual } \\
\text { Contribution in }\end{array}$} & \multicolumn{2}{|c|}{ VCM-Same } & \multicolumn{2}{|c|}{ VCM-Different } \\
\hline & (1) & (2) & (3) & (4) \\
\hline & VCM-1 & VCM-2 & VCM-1 & VCM-2 \\
\hline VCM-1-lag & $\begin{array}{l}0.29 * * \\
(0.14)\end{array}$ & $\begin{array}{c}0.11 \\
(0.13)\end{array}$ & $\begin{array}{c}0.27^{* * * *} \\
(0.03)\end{array}$ & $\begin{array}{l}0.08^{*} \\
(0.04)\end{array}$ \\
\hline VCM-2-lag & $\begin{array}{c}0.04 \\
(0.08)\end{array}$ & $\begin{array}{c}0.30 * * * \\
(0.08)\end{array}$ & $\begin{array}{c}0.07 * * \\
(0.03)\end{array}$ & $\begin{array}{c}0.47 * * * \\
(0.02)\end{array}$ \\
\hline group-VCM-1-lag & $\begin{array}{c}0.13^{* * * *} \\
(0.02)\end{array}$ & $\begin{array}{c}0.01 \\
(0.02)\end{array}$ & $\begin{array}{c}0.12^{* * * *} \\
(0.01)\end{array}$ & $\begin{array}{c}-0.04^{* * * *} \\
(0.00)\end{array}$ \\
\hline group-VCM-2-lag & $\begin{array}{c}0.01 \\
(0.03)\end{array}$ & $\begin{array}{c}0.08^{* * *} \\
(0.03)\end{array}$ & $\begin{array}{c}-0.01^{* *} \\
(0.01)\end{array}$ & $\begin{array}{c}0.09 * * * \\
(0.00)\end{array}$ \\
\hline Period & $\begin{array}{l}-9.01 \\
(6.50)\end{array}$ & $\begin{array}{l}-0.09 \\
(5.45)\end{array}$ & $\begin{array}{l}-5.76 \\
(5.99)\end{array}$ & $\begin{array}{c}9.58 \\
(6.42)\end{array}$ \\
\hline Constant & $\begin{array}{c}1.38 \\
(0.86)\end{array}$ & $\begin{array}{c}1.26 \\
(1.20)\end{array}$ & $\begin{array}{c}3.16^{* * *} \\
(1.01)\end{array}$ & $\begin{array}{l}1.84 * * \\
(0.80)\end{array}$ \\
\hline Observations & 760 & 760 & 1216 & 1216 \\
\hline Number of clusters & 10 & 10 & 4 & 4 \\
\hline Overall $R$-squared & 0.49 & 0.36 & 0.29 & 0.47 \\
\hline
\end{tabular}




\section{Figure 1: Decision-Making Screen}

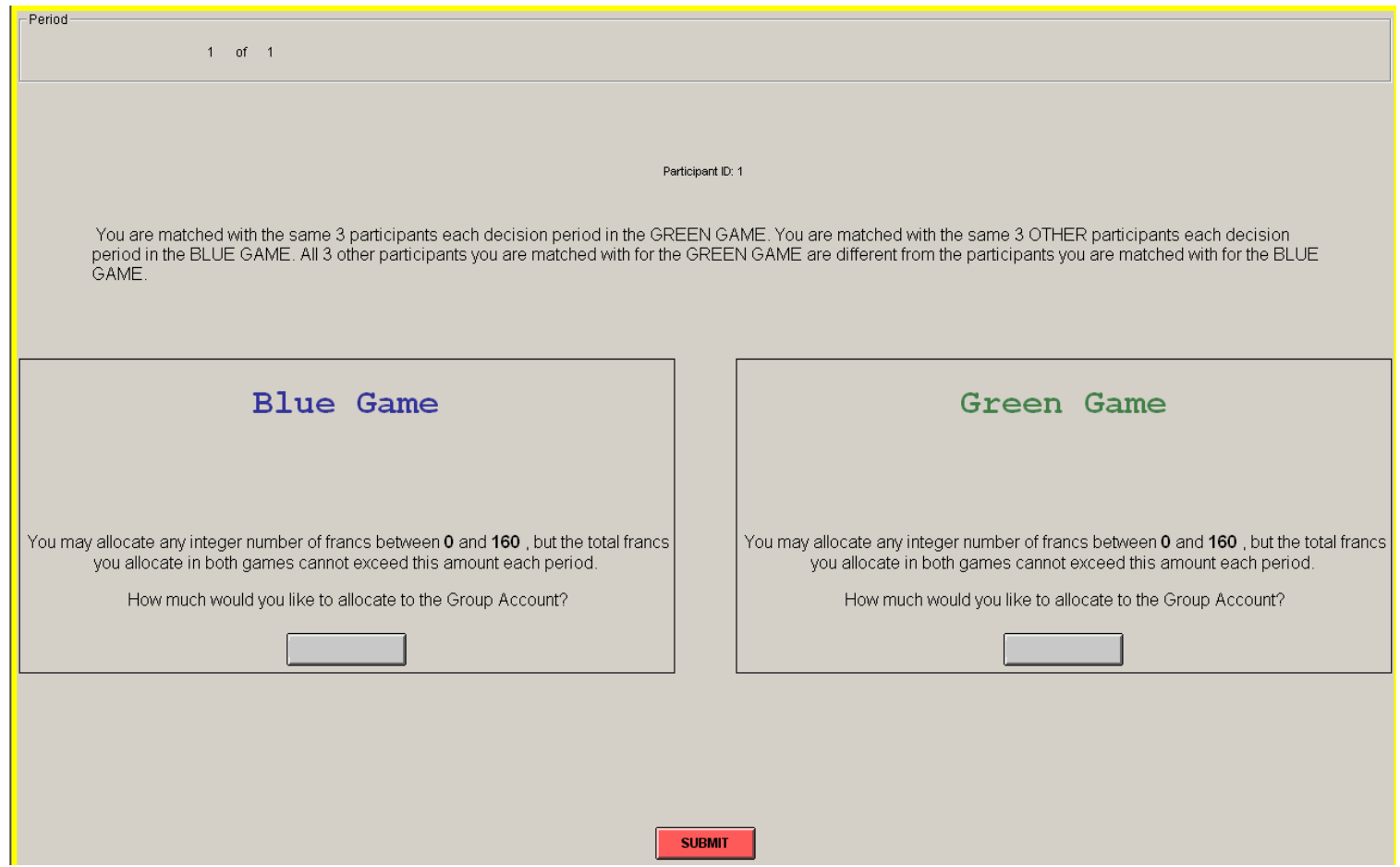

Figure 2: Average Contribution over All Rounds

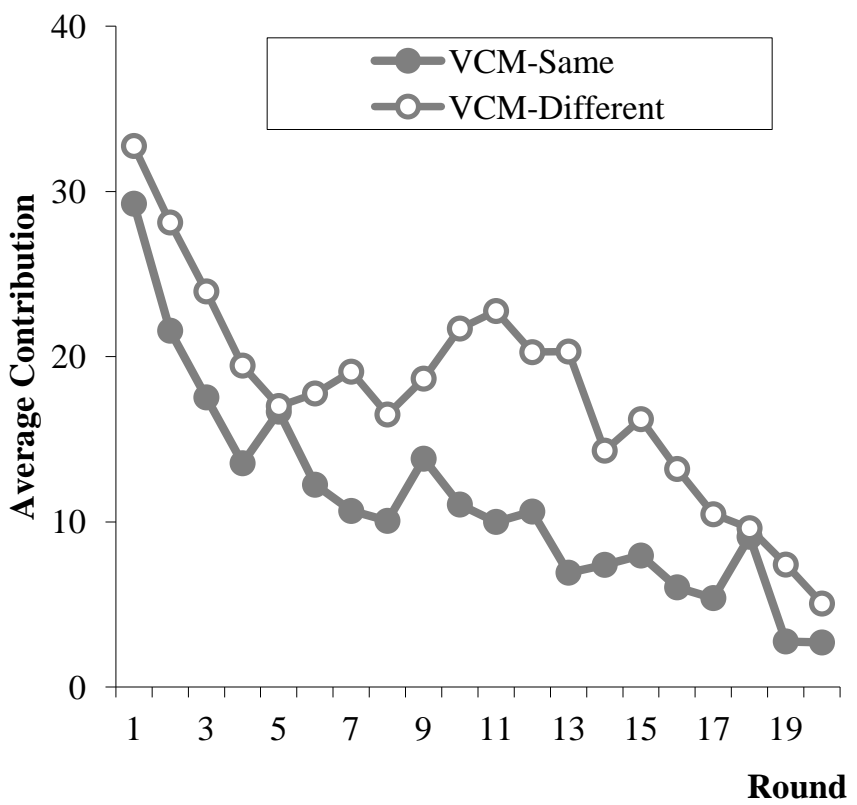




\section{Appendix - Instructions (VCM-Same Treatment)}

In this experiment you will participate in two games. Each of the two games will have four participants, including you. You will not know the identity of the participants you are grouped with. The experiment will consist of 20 periods. You will participate in a BLUE GAME and a GREEN GAME at the same time. BLUE GAME and GREEN GAME have exactly the same rules. You will participate in the BLUE GAME with the same three participants. You will participate in the GREEN GAME with the same three participants. All three other participants you are matched with for the GREEN GAME are the same as the participants you are matched with for the BLUE GAME. The BLUE GAME will appear on the left side of the screen and the GREEN GAME will appear on the right side of the screen at the same time in all 20 periods.

At the end of the experiment $\mathbf{2}$ out of $\mathbf{2 0}$ periods will be randomly selected for payment. After you have completed all periods two tokens will be randomly drawn out of a bingo cage containing tokens numbered from $\mathbf{1}$ to 20. The token numbers determine which two periods are going to be paid.

Each period you will be given $\mathbf{1 6 0}$ francs. Francs will be converted to U.S. dollars at the end of the experiment at the rate of $\mathbf{2 5}$ francs $=\mathbf{\$ 1}$. Each period, you will select an allocation for BLUE GAME and an allocation for GREEN GAME. When you are ready to make your decision, click on the "input boxes" below "How much would you like to allocate to Group Account in BLUE GAME?" and "How much would you like to allocate to Group Account in GREEN GAME?” and the program will allow you to enter in your number choices. When you are finished making your choices, click "Submit". You can allocate as much or as little of your francs as you like in each period, but remember that the total francs you choose to allocate must not exceed 160 francs in each period. You keep any francs which you do not allocate; therefore, your earnings are the sum of the francs you decided to keep, your earnings from BLUE GAME, and your earnings from GREEN GAME.

\section{BLUE (GREEN) GAME}

Below, we will read instructions for the BLUE GAME. However, the rules for the BLUE GAME and the GREEN GAME are exactly the same.

Each period you will decide how much of your endowment you want to allocate to a Group Account. You may allocate any integer number of francs between $\mathbf{0}$ and 160, as long as the total number of francs used for allocations in both games does not exceed 160. After all participants have made their decisions, your outcome for the period is calculated.

Your period outcome from BLUE GAME depends on the total number of francs allocated to the Group Account by all 4 group members (including you). In particular, your earnings from the Group Account are $\mathbf{4 0}$ percent of the total allocation of all $\mathbf{4}$ group members (including you) to the Group Account. Therefore, for every franc you allocate to the Group Account, you increase the total allocation to the Group Account by 1 franc. Therefore, your earnings from the Group Account rise by $0.4 \times 1=0.4$ francs. And the earnings of the other group members also rise by 0.4 francs each, so that the total earnings of the group from the Group Account rise by 1.6 francs.

In summary, your period outcome in BLUE GAME is determined as follows:

BLUE GAME Outcome = (earnings from Group Account) - (your allocation to the Group Account $)=$ $=0.4 \times$ (allocation of 4 group members to Group Acct.) - (your allocation to Group Acct.)

Example: Suppose that you allocated 40 francs to the Group Account and that the other three members of your group allocated a total of 120 francs. This makes a total of 160 francs in the Group Account. In this case each member of the group receives earnings from the Group Account of $0.4 \times 160=64$ francs, which is also each member's period outcome in the BLUE GAME.

\section{TOTAL EARNINGS}

After you choose how much to allocate to the Group Account in the BLUE GAME and how much to allocate to the Group Account in the GREEN GAME, the remainder of your 160 francs will be allocated to your Individual Account. Your earnings from the Individual Account equal to the francs that you keep for yourself and do not depend on the decisions of others. Therefore, for every franc you keep for yourself in your Individual Account, you earn 1 franc.

Your total earnings will be converted to cash and paid at the end of the experiment if the current period is the period that is randomly chosen for payment. Your total earnings for each period will be calculated as:

Total Earnings $=(160)+($ Outcome from BLUE GAME $)+($ Outcome from GREEN GAME $)=$ Which is the same as 
$=160+($ Earnings from Group Account in BLUE GAME) - (allocation to Group Account in BLUE GAME)

+(Earnings from Group Account in GREEN GAME)-(allocation to Group Account in GREEN GAME)

\section{OUTCOME SCREEN}

At the end of each period, your allocation, the sum of all allocations in your group for each of BLUE GAME and GREEN GAME, and the outcome for each of BLUE GAME and GREEN GAME are reported on the outcome screen. The computer will also display your income from the individual account and your total earnings for the period. Once the outcome screen is displayed you should record your results for the period on your Personal Record Sheet under the appropriate heading.

At the end of the experiment $\mathbf{2}$ out of $\mathbf{2 0}$ periods will be randomly selected for payment. Your earnings for these two periods will be converted to U.S. dollars at the end of the experiment at the rate of $\mathbf{2 5}$ francs $=\mathbf{\$ 1}$. 
2013

\section{Economic Science Institute Working Papers}

13-07 Gabaix, X., Laibson, D., Li, D., Li, H., Resnick, S., and de Vries, C. The Impact of Competition on Prices with Numerous Firms.

13-06 Sheremeta, R. Overbidding and Heterogeneous Behavior in Contest Experiments.

13-05 Deck, C. and Porter, D. Prediction Markets in the Laboratory.

13-04 Corgnet, B., Hernán-Gonzalez, R., Kujal, P., and Porter, D. The Effect of Earned vs. House Money on Price Bubble Formation in Experimental Asset Markets.

13-03 Sheremeta, R. and Zhang, J. Three-Player Trust Game with Insider Communication.

13-02 McCarter, M. and Sheremeta, R. You Can't Put Old Wine in New Bottles: The Effect of Newcomers on Coordination in Groups.

13-01 Corgnet, B., Hernan-Gonzalez, R., and Rassenti, S. Peer Pressure and Moral Hazard in Teams: Experimental Evidence.

\section{2}

12-31 Thomas, C. An Alternating-Offers Model of Multilateral Negotiations.

12-30 Mago, S., Sheremeta, R. and Yates, A. Best-of-Three Contest Experiments: Strategic versus psychological momentum.

12-29 Bigoni, M., Camera, G. and Casari, M. Strategies of Cooperation and Punishment among Students and Clerical Workers.

12-28 Camera, G. and Kim, J. Buyer's Equilibrium with Capacity Constraints and Restricted Mobility: A recursive approach.

12-27 Camera, G., Casari, M., and Bigoni, M. Binding Promises and Cooperation Among Strangers.

12-26 Schniter, E., Shields, T. and Dickhaut, J. Ageism \& Cooperation.

12-25 Gjerstad, S. and Smith, V. Balance Sheet Crises: Causes, Consequences and Responses.

12-24 Gómez-Miñambres, J., Corgnet, B. and Hernán-Gonzalez, R. Goal Setting and Monetary Incentives: When Large Stakes Are Not Enough. 
12-23 Clots-Figueras, I., Hernán González, R., and Kujal, P. Asymmetry and Deception in the Investment Game.

12-22 Dechenaux, E., Kovenock, D. and Sheremeta, R. A Survey of Experimental Research on Contests, All-Pay Auctions and Tournaments.

12-21 Rubin, J. and Sheremeta, R. Principal-Agent Settings with Random Shocks.

12-20 Gómez-Miñambres, J. and Schniter, E. Menu-Dependent Emotions and Self-Control.

12-19 Schniter, E., Sheremeta, R., and Sznycer, D. Building and Rebuilding Trust with Promises and Apologies.

12-18 Shields, T. and Xin, B. Higher-order Beliefs in Simple Trading Models.

12-17 Pfeiffer, G. and Shields, T. Performance-Based Compensation and Firm Value: Experimental evidence.

12-16 Kimbrough, E. and Sheremeta, R. Why Can't We Be Friends? Entitlements, bargaining, and conflict.

12-15 Mago, S., Savikhin, A., and Sheremeta, R. Facing Your Opponents: Social identification and information feedback in contests.

12-14 McCarter, M., Kopelman, S., Turk, T. and Ybarra, C. Too Many Cooks Spoil the Broth: How the tragedy of the anticommons emerges in organizations.

12-13 Chowdhury, S., Sheremeta, R. and Turocy, T. Overdissipation and Convergence in Rent-seeking Experiments: Cost structure and prize allocation rules.

12-12 Bodsky, R., Donato, D., James, K. and Porter, D. Experimental Evidence on the Properties of the California's Cap and Trade Price Containment Reserve.

12-11 Branas-Garza, P., Espin, A. and Exadaktylos, F. Students, Volunteers and Subjects: Experiments on social preferences.

12-10 Klose, B. and Kovenock, D. Extremism Drives Out Moderation.

12-09 Buchanan, J. and Wilson, B. An Experiment on Protecting Intellectual Property.

12-08 Buchanan, J., Gjerstad, S. and Porter, D. Information Effects in Multi-Unit Dutch Auctions.

12-07 Price, C. and Sheremeta, R. Endowment Origin, Demographic Effects and Individual Preferences in Contests.

12-06 Magoa, S. and Sheremeta, R. Multi-Battle Contests: An experimental study. 
12-05 Sheremeta, R. and Shields, T. Do Liars Believe? Beliefs and Other-Regarding Preferences in Sender-Receiver Games.

12-04 Sheremeta, R., Masters, W. and Cason. T. Winner-Take-All and Proportional-Prize Contests: Theory and experimental results.

12-03 Buchanan, J., Gjerstad, S. and Smith, V. There's No Place Like Home.

12-02 Corgnet, B. and Rodriguez-Lara, I. Are you a Good Employee or Simply a Good Guy? Influence Costs and Contract Design.

12-01 Kimbrough, E. and Sheremeta, R. Side-Payments and the Costs of Conflict.

\section{1}

11-20 Cason, T., Savikhin, A. and Sheremeta, R. Behavioral Spillovers in Coordination Games.

11-19 Munro, D. and Rassenti, S. Combinatorial Clock Auctions: Price direction and performance.

11-18 Schniter, E., Sheremeta, R., and Sznycer, D. Restoring Damaged Trust with Promises, Atonement and Apology.

11-17 Brañas-Garza, P., and Proestakis, A. Self-discrimination: A field experiment on obesity.

11-16 Brañas-Garza, P., Bucheli, M., Paz Espinosa, M., and García-Muñoz, T. Moral Cleansing and Moral Licenses: Experimental evidence.

11-15 Caginalp, G., Porter, D., and Hao, L. Asset Market Reactions to News: An experimental study.

11-14 Benito, J., Branas-Garz, P., Penelope Hernandez, P., and Sanchis Llopis, J. Strategic Behavior in Schelling Dynamics: A new result and experimental evidence.

11-13 Chui, M., Porter, D., Rassenti, S. and Smith, V. The Effect of Bidding Information in Ascending Auctions.

11-12 Schniter, E., Sheremeta, R. and Shields, T. Conflicted Minds: Recalibrational emotions following trust-based interaction.

11-11 Pedro Rey-Biel, P., Sheremeta, R. and Uler, N. (Bad) Luck or (Lack of) Effort?: Comparing social sharing norms between US and Europe.

11-10 Deck, C., Porter, D., and Smith, V. Double Bubbles in Assets Markets with Multiple Generations.

11-09 Kimbrough, E., Sheremeta, R., and Shields, T. Resolving Conflicts by a Random Device.

11-08 Brañas-Garza, P., García-Muñoz, T., and Hernan, R. Cognitive effort in the Beauty Contest Game. 
11-07 Grether, D., Porter, D., and Shum, M. Intimidation or Impatience? Jump Bidding in On-line Ascending Automobile Auctions.

11-06 Rietz, T., Schniter, E., Sheremeta, R., and Shields, T. Trust, Reciprocity and Rules.

11-05 Corgnet, B., Hernan-Gonzalez, R., and Rassenti, S. Real Effort, Real Leisure and Real-time Supervision: Incentives and peer pressure in virtual organizations.

11-04 Corgnet, B. and Hernán-González R. Don’t Ask Me If You Will Not Listen: The dilemma of participative decision making.

11-03 Rietz, T., Sheremeta, R., Shields, T., and Smith, V. Transparency, Efficiency and the Distribution of Economic Welfare in Pass-Through Investment Trust Games.

11-02 Corgnet, B., Kujal, P. and Porter, D. The Effect of Reliability, Content and Timing of Public Announcements on Asset Trading Behavior.

11-01 Corgnet, B., Kujal, P. and Porter, D. Reaction to Public Information in Markets: How much does ambiguity matter?

\section{0}

10-23 Sheremeta, R. Perfect-Substitutes, Best-Shot, and Weakest-Link Contests between Groups.

10-22 Mago, S., Sheremeta, R., and Yates, A. Best-of-Three Contests: Experimental evidence.

10-21 Kimbrough, E. and Sheremeta, R. Make Him an Offer He Can't Refuse: Avoiding conflicts through side payments.

10-20 Savikhim, A. and Sheremeta, R. Visibility of Contributions and Cost of Inflation: An experiment on public goods.

10-19 Sheremeta, R. and Shields, T. Do Investors Trust or Simply Gamble?

10-18 Deck, C. and Sheremeta, R. Fight or Flight? Defending Against Sequential Attacks in the Game of Siege.

10-17 Deck, C., Lin, S. and Porter, D. Affecting Policy by Manipulating Prediction Markets: Experimental evidence.

10-16 Deck, C. and Kimbrough, E. Can Markets Save Lives? An Experimental Investigation of a Market for Organ Donations.

10-15 Deck, C., Lee, J. and Reyes, J. Personality and the Consistency of Risk Taking Behavior: Experimental evidence.

10-14 Deck, C. and Nikiforakis, N. Perfect and Imperfect Real-Time Monitoring in a Minimum-Effort Game. 
10-13 Deck, C. and Gu, J. Price Increasing Competition? Experimental Evidence.

10-12 Kovenock, D., Roberson, B., and Sheremeta, R. The Attack and Defense of Weakest-Link Networks.

10-11 Wilson, B., Jaworski, T., Schurter, K. and Smyth, A. An Experimental Economic History of Whalers' Rules of Capture.

10-10 DeScioli, P. and Wilson, B. Mine and Thine: The territorial foundations of human property.

10-09 Cason, T., Masters, W. and Sheremeta, R. Entry into Winner-Take-All and Proportional-Prize Contests: An experimental study.

10-08 Savikhin, A. and Sheremeta, R. Simultaneous Decision-Making in Competitive and Cooperative Environments.

10-07 Chowdhury, S. and Sheremeta, R. A generalized Tullock contest.

10-06 Chowdhury, S. and Sheremeta, R. The Equivalence of Contests.

10-05 Shields, T. Do Analysts Tell the Truth? Do Shareholders Listen? An Experimental Study of Analysts' Forecasts and Shareholder Reaction.

10-04 Lin, S. and Rassenti, S. Are Under- and Over-reaction the Same Matter? A Price Inertia based Account.

10-03 Lin, S. Gradual Information Diffusion and Asset Price Momentum.

10-02 Gjerstad, S. and Smith, V. Household Expenditure Cycles and Economic Cycles, 1920-2010.

10-01 Dickhaut, J., Lin, S., Porter, D. and Smith, V. Durability, Re-trading and Market Performance. 2009

09-11 Hazlett, T., Porter, D., and Smith, V. Radio Spectrum and the Disruptive Clarity OF Ronald Coase.

09-10 Sheremeta, R. Expenditures and Information Disclosure in Two-Stage Political Contests.

09-09 Sheremeta, R. and Zhang, J. Can Groups Solve the Problem of Over-Bidding in Contests?

09-08 Sheremeta, R. and Zhang, J. Multi-Level Trust Game with "Insider" Communication.

09-07 Price, C. and Sheremeta, R. Endowment Effects in Contests.

09-06 Cason, T., Savikhin, A. and Sheremeta, R. Cooperation Spillovers in Coordination Games.

09-05 Sheremeta, R. Contest Design: An experimental investigation. 
09-04 Sheremeta, R. Experimental Comparison of Multi-Stage and One-Stage Contests.

09-03 Smith, A., Skarbek, D., and Wilson, B. Anarchy, Groups, and Conflict: An experiment on the emergence of protective associations.

09-02 Jaworski, T. and Wilson, B. Go West Young Man: Self-selection and endogenous property rights.

09-01 Gjerstad, S. Housing Market Price Tier Movements in an Expansion and Collapse.

\section{8}

08-09 Dickhaut, J., Houser, D., Aimone, J., Tila, D. and Johnson, C. High Stakes Behavior with Low Payoffs: Inducing preferences with Holt-Laury gambles.

08-08 Stecher, J., Shields, T. and Dickhaut, J. Generating Ambiguity in the Laboratory.

08-07 Stecher, J., Lunawat, R., Pronin, K. and Dickhaut, J. Decision Making and Trade without Probabilities.

08-06 Dickhaut, J., Lungu, O., Smith, V., Xin, B. and Rustichini, A. A Neuronal Mechanism of Choice.

08-05 Anctil, R., Dickhaut, J., Johnson, K., and Kanodia, C. Does Information Transparency Decrease Coordination Failure?

08-04 Tila, D. and Porter, D. Group Prediction in Information Markets With and Without Trading Information and Price Manipulation Incentives.

08-03 Thomas, C. and Wilson, B. Horizontal Product Differentiation in Auctions and Multilateral Negotiations.

08-02 Oprea, R., Wilson, B. and Zillante, A. War of Attrition: Evidence from a laboratory experiment on market exit.

08-01 Oprea, R., Porter, D., Hibbert, C., Hanson, R. and Tila, D. Can Manipulators Mislead Prediction Market Observers? 